\title{
Enneking Tumor Type
}

National Cancer Institute

\section{Source}

National Cancer Institute. Enneking Tumor Type. NCI Thesaurus. Code C140262.

A description of malignant mesenchymal tumors based on tumor extent. 